\title{
Essential tips for a rock-solid geoscience PhD: Part III
}

\section{In the last part of this three-part focus, Melanie J Leng \& Anson Mackay give some final advice}

We've previously explained how important it is to carefully choose your $\mathrm{PhD}$ project and supervisor, to manage your time and relationships, and given more detailed advice on the practical side of doing a PhD. To finish, we'll cover social media, CVs and some guidance on what to do if a $\mathrm{PhD}$ isn't, after all, for you.

\section{Social media}

Join up! From day one start to build your online presence (there will be one anyway, so create your own). If using Facebook decide whether it's private (family and friends), work, or a mix. If a mix, bear in mind that posts can be shared, and people may be checking you out. Microblogging and photo/video-sharing platforms, such as Twitter and Instagram, are popular with geoscientists for sharing moments in the field or lab and seeing what other geoscientists are doing. Searchable hashtags (\#) are a great way of getting involved with many different communities, ideas and campaigns. Twitter and Instagram are open for all to access unless you lock down your account. If your university personal profile pages are brief then consider using freeware such as WordPress or About.me to create your own personal profile. Keep it up to date with conferences, papers, blogs, social media, contact information, and plenty of action photos.

Blogs are a great way to practise writing short (400-800 words) "stories" on things you have been up to, or fancy talking about. Use lots of interesting photos. Most universities have blog sites for staff and students to contribute to, else create your own using freeware or your website. Video is increasingly popular. Short, one-to-two minute clips shot on a smart phone can be effective for showing others what you do.

Social media can help build your CV by improving your network outside of your institution and internationally as well; if done well, it will help you stand out from the crowd. But balance your time spent on social media with other forms of writing. Platforms such as Twitter are great for finding out about the latest developments in your field, from a professional, scientific level, to more personal issues related to workloads and stress. But social media has downsides, too, and it is good to recognise these early on to limit the detrimental impacts. Read up on tips for getting the most out of a platform, as well as codes of conduct (held by universities) one should follow.

\section{Curriculum Vitae}

There is no one-size-fits-all solution for the perfect CV, but it should always be clearly formatted and short enough to be scanned quickly-and

scanned quickly - and
most importantly-
tailored to the role
you're applying for.
Many websites offer
advice on writing $\mathrm{CVs}$,
but take care to keep it
relevant and academic.
And keep it up-to-date
because you may need it for
various purposes; if you apply
to be on a committee or panel,
for example, and eventually
towards the end of your PhD when
you will apply for future roles.

CVs should never be completely formulaic, but they should always contain: personal details (name, email, contact phone number and address, social media handles); personal statement (this helps you to stand out from the crowd by explaining who you are, what you're offering and what you're looking for); education (dates, the type of qualification and/or the grade you achieved); publications (published conference abstracts, papers, preprints, blogs); work experience (with the most recent first); achievements (explain how your previous experience has given you the skills needed to make you a suitable candidate for the position you are applying for); any relevant prizes or scholarships, hobbies and interests that demonstrate your skills and provide interview talking points.

\section{Get involved}

Learn to say yes! Grab opportunities as they arise; everyone loves positivity and you will demonstrate energy and teamwork. Apply for positions of responsibility when they arise; early career representatives are often sought. Such positions can provide great experience to find out how learned societies work, and give you opportunities to influence what and how decisions are made.

Learn to say no! As important, is knowing when not to say "yes" all the time, especially if it's a yes for the wrong reasons, or you are just simply over-committed. Saying yes should be an opportunity-not just a request from others. If you are not used to relying on intuition, then think about how a request makes you feel. Knowing when to say no is important for developing healthy, balanced relationships with colleagues. Remember that when you say "no" to things you don't want to do, it frees your time to focus on the pursuits that you really want to do and can be liberating. Never give an immediate answer-think over the request for a day or so and use friends as sounding boards.

\section{What if it all goes wrong?} If for whatever reason $\mathrm{PhD}$ research turns out not to be for you, there is often an option to "press pause". That is, you can interrupt your $\mathrm{PhD}$ with a break, which might eventually result in withdrawing from your $\mathrm{PhD}$ altogether, writing up an MSc or

MPhil instead, or transferring to a different PhD project or supervisor. The main thing is to talk 
to your supervisors, your postgraduate tutor, your Head of School, and welfare services within the university. Universities have careers services that can advise on the options and possibilities open to you, and any potential implications, as well as appropriate timings and time-limits of interruptions. Universities have forms to complete and approvals to seek, so follow the procedure. If you are an international student, on a Tier 4 visa for example, contact your graduate tutor immediately. They will be able to guide you on who to talk to within your university so that you do not break any visa rules.

\section{In summary}

Our advice given in this three-part series is not exhaustive, but it comes from many years of personal experiences.

Remember that you have some choice when deciding on a PhD supervisor, take care to build professional relationships and manage your interactions and expectations. Presentations, writing and social media are significant parts to your PhD that must be tackled headon. Training and building a CV are vital to enhance your further employment prospects. We briefly touched on critical care, which is all too important these days. Learning to say "no", as well as "yes", is essential.

There are many things to consider when embarking on $\mathrm{PhD}$ research, but the experience will increase your confidence, communication and managements skills, and improve your abilities to understand and solve problems. Enjoy your PhD. It may be tough at times, but it will be an amazing experience. When you pass your viva, be proud of this major achievement and call yourself doctor-you earned it.
Melanie Leng ${ }^{1}$ is Director of Geochemistry at the British Geological Survey, UK, and Professor in Isotope Geoscience at the University of Nottingham, UK.

Anson Mackay ${ }^{2}$ is Professor in Environmental Change at UCL, UK, and an Honorary Research Associate at the British Geological Survey.

1 mjl@bgs.ac.uk

2 ans.mackay@ucl.ac.uk

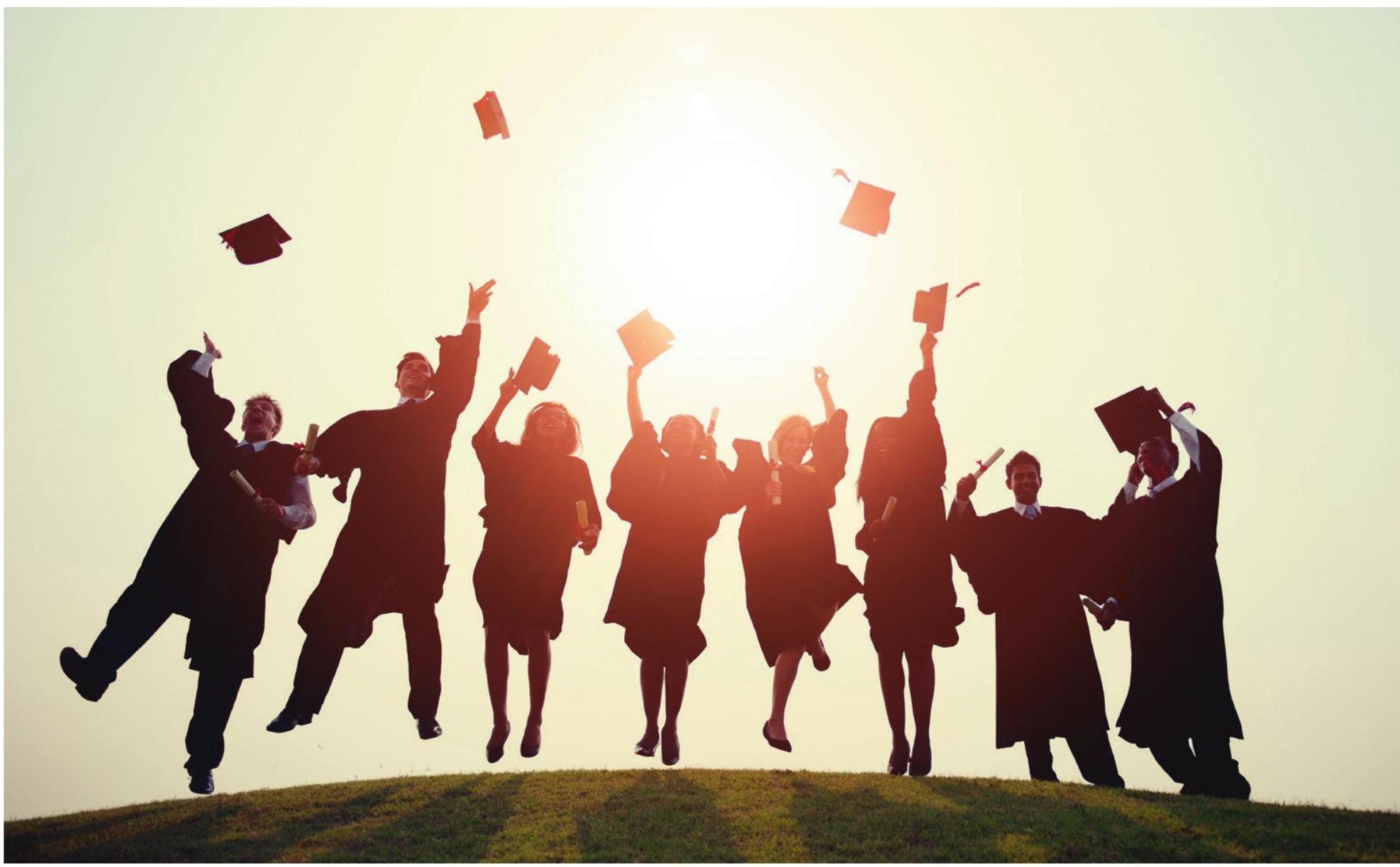

